\title{
GROWTH SCENARIOS FOR THE CITY OF GUANGZHOU, CHINA: TRANSFERABILITY AND CONFIRMABILITY
}

\author{
A. Lehner ${ }^{\mathrm{a}, \mathrm{b}}$, V.Kraus ${ }^{\mathrm{a}}$, C. Wei ${ }^{\mathrm{b}}$, K. Steinnocher ${ }^{\mathrm{a}}$ \\ ${ }^{a}$ AIT Austrian Institute of Technology, Energy Department, Giefinggasse 2, 1210 Vienna, Austria - (arthur.lehner.fl, \\ valentin.kraus.fl, klaus.steinnocher)@ait.ac.at \\ b University of Salzburg, Department of Geoinformatics, Schillerstrasse 30, 5020 Salzburg, Austria - chunzhu.wei@ stud.sbg.ac.at
}

KEY WORDS: Urban remote sensing, Urban planning, Urban growth, Pearl River Delta, Guangzhou, China

\begin{abstract}
:
This work deals with the development of urban growth scenarios and the prevision of the spatial distribution of built-up area and population for the urban area of the city of Guangzhou in China. Using freely-available data, including remotely sensed data as well as census data from the ground, expenditure of time and costs shall remain low. Guangzhou, one of the biggest cities within the Pearl River Delta, has faced an enormous economic and urban growth during the last three decades. Due to its economical and spatial characteristics it is a promising candidate for urban growth scenarios. The monitoring and prediction of urban growth comprises data of population and give them a spatial representation. The model, originally applied for the Indian city Ahmedabad, is used for urban growth scenarios. Therefore, transferability and confirmability of the model are evaluated. Challenges that may occur by transferring a model for urban growth from one region to another are discussed. With proposing the use of urban remote sensing and freely available data, urban planners shall be fitted with a comprehensible and simple tool to be able to contribute to the future challenge Smart Growth.
\end{abstract}

\section{INTRODUCTION}

\subsection{Economic Growth and Urban Expansion}

Coming from the traditional urban form of the walled city, later "influenced" by European planning approaches, replaced by principles of socialist city planning and economic decisionmaking (Wu, 2015) and transferred into the modern China, urban planning in China has encountered several changes. The city of Guangzhou within the Pearl River Delta represents one of these cities alongside the Chinese coast that have seen all these different planning approaches.

The economic growth of the last two decades has let China become the largest national economy on earth and this fast economic growth was accompanied by a gain of built-up area, an increased consumption of energy and resources as well as by internal migration and generally by a rapid growth of urban agglomerations. Opinions are voiced that urban planning shall play a more important role, sustainable and "planned" growth shall gain importance and the concept of Smart Growth may smooth this way.

\subsection{Smart Urban Growth}

Due to fast economic growth, internal migration and very active building activity urban planners in China face many challenges. Challenges like provision, transport and consumption of energy become an important matter of planning authorities since they are strongly spatial related topics. With regards to demand and supply of energy resources, including their spatial distribution, city-wide energy-planning requires understanding of the complex system interdependencies at urban level (Agugiaro, 2015). Western concepts such as 'smart growth' or 'new urbanism' have been imported to China (Song and Ding, 2009; $\mathrm{Wu}, 2015)$. However, in most western and Asian countries for a long period of time energy planning was hardly part of urban planning strategies or development plans; in terms of Smart City and Smart Growth an unacceptable state.
The term Smart Growth may not have the similar meaning to professionals coming from different professional fields. However, there are overall principles that are commonly agreed on. Some of these principles are listed below.

- Limiting outward extension of new development in order to make settlements more compact and preserve open spaces.

- $\quad$ Raising residential densities in both new-growth areas and existing neighborhoods.

- Providing for more mixed land uses and pedestrian friendly layouts to minimize the use of cars on short trips. (Downs, 2005)

Several plans to regulate and guide the urbanization process of Guangzhou were applied by the provincial government. However, the urbanization within the whole Pearl River Delta is still strongly driven by export-oriented industrial development which results in scattered and rampant pattern of regional development $(\mathrm{Wu}, 2015)$. This trend is stimulated by a range of Urban Development Plans that encourage the interlocking between particular cities of the Pearl River Delta, e.g. Guangzhou, Shenzhen, Macau and Honk Kong. Recent urban growth analysis of the Pearl River Delta highlights the risk of planning policies that foster urban sprawl and a high rate of consumption of arable land (Du et al., 2013). However, e.g. the Pearl River Delta Urban Cluster Coordination Plan also supported the establishment of defined open space, preservation of green belts and transport corridors. In order to identify spatial patterns and development axis, the connection of latter to the population change makes the first move towards Smart Growth. The development of built-up area and population can be retraced and offers planners a (more) holistic view on urban growth. Urban remote sensing can clarify the actual spatial effects of planning policies from the past and thus pave the way for Smart Urban Growth. 


\subsection{Urban Remote Sensing in China}

Within these last twenty years of spatial and economic changes, remote sensing datasets have been used in urban planning and management in China and remotely sensed data have played an important role in analyzing the urban structure of Chinese cities. Already since the 1980ies remotely sensed data have played an important role in detecting urban morphologies effectively in China (Xiao and Zhan, 2009). These data are used for conservation planning of cultural heritages and historic sites, monitoring the effectiveness of approved plans and for the identification of illegal building activity, as presented by Xiao and Zhan (2009), or are generally used for spatial and temporal analysis of urban growth (Chen et al., 2000). Chen et al. (2016) have shown the usability of combining remotely sensed data and data from the ground to analyse the patterns of urban land expansion and their link to economic parameters.

\section{DATA \& STUDY AREA}

\subsection{Study Area}

Guangzhou, with a total area of 7,434.4 square kilometres, is the largest city in South Central China (Figure 1.). As one of the fastest growing cities in China, today Guangzhou is home for more than 15 million people. Since the Free Trade Zones were founded in Guangzhou in 1990s, it has become the main manufacturing hub of the Pearl River Delta as one of China's leading commercial and industrial city. But due to the rapid industrialization and urban sprawl, it also suffers from a series of urbanization problems, such as pell-mell growth, air pollution, etc.

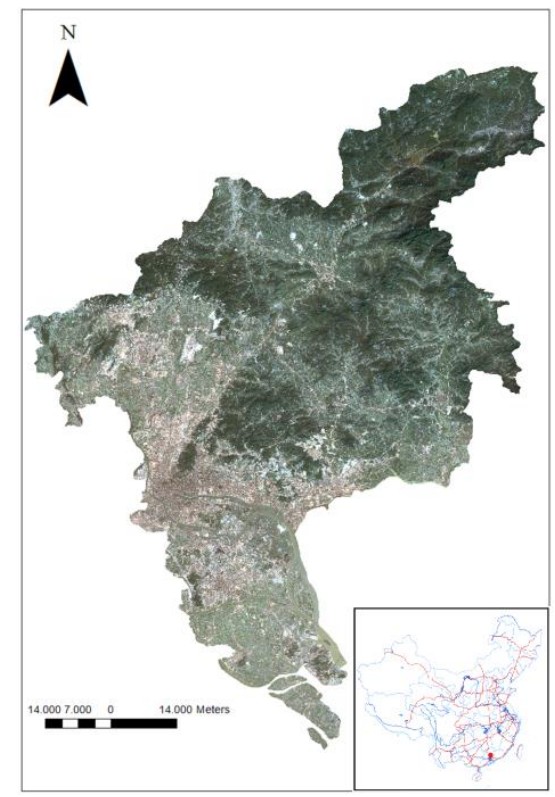

Figure 1 . The study area of Guangzhou, China

\subsection{Data collection}

The $1 \mathrm{~km}$ land-use and land-cover (LULC) data classification was obtained from by Resources and Environment Science Data Center, Chinese Academy of Sciences (http://www.raesdc.cn/) in 1990, 1995, 2000, 2005 and 2010. All the original census data (including population and energy consumption) came from the Guangdong Statistical Yearbook from 1990 to 2010 (http://www.gdstats.gov.cn/tjsj/gdtjnj/). The Population value is calculated by household registered at the year-end.

\section{METHODOLOGY}

\subsection{Methodological Approach}

Many studies show the usability of GIS and remote sensing applications as a support for local authorities (Adhvaryu, 2010; O'Looney, 1997; Zheng et al., 2015). To support local governments efficiently as well as spatial planners and other professionals being involved in planning processes and to reduce costs, our approach was to work with freely accessible data from remote sensing and public census data which were provided by the Statistics Bureau of Guangzhou Municipality. Thus, from a minimum of data and information a plausibility test should be developed with which predictions about urban growth, spatial trends and their materialization within the urban environment could be verified.

The presented scenarios are based on the knowledge of previous urban growth scenarios that are more complex, include several parameters, different weighting factors and include profound knowledge about the particular zoning map or other expert-based knowledge of the study area (Gebetsroither-Geringer and Loibl, n.d.; Herold et al., 2003; Rafiee et al., 2009). This work presents the transfer and the application of a simplified urban growth model because this requires a minimum of data that are - in most countries of the world - freely available.

Based on the existing model that was used for developing a future urban growth scenario of the Indian city Ahmedabad (Lehner et al., 2016) different timeframes for urban growth scenarios were chosen. Within the aforementioned study it was evaluated if a certain number of inhabitants will be able to settle within the present administrative area. However, the model now was tested regarding its usability for different research questions and its transferability. The computed results were compared with the actual data of Land UselLand Cover (LULC) and census data. The use of LULC data derived from Landsat Images and resulting information about built-up and non-built-up area for studying urban growth has been explored in former studies (Hu et al., 2016; Jat et al., 2008; Yang, n.d.). However, we wanted to relate the development of the urban footprint, which means the development of built-up area through time, to the population change. Further our goal was to answer the question whether the existing model could be transferred from one city to another and what results could be achieved. It should be evaluated if the model was a useful and reliable tool for urban planners. Therefore, the study area of the city of Guangzhou was chosen in a deliberate manner; the study area of the Chinese metropole differs in spatial, economic and climate characteristics in comparison to the Indian City Ahmedabad.

The decision of performing and comparing different scenarios based on different timeframes which were used as training samples, should also support researchers in the future in decision making processes regarding the election of the best period of time for triggering urban growth models. Under these terms and conditions aforementioned data was chosen and following methodology applied.

\subsection{Investigating Urban Expansion and Population Change}

Population change can be correlated with the change of built-up area. Assuming a linear correlation between those two factors, the calculation should not be used only to give an informative review regarding the land consumption per capita or to draw conclusion from the structural environment. It could also serve as initial approach for scenario based investigations. 


\subsection{Preparation of Built-Up/Non-Built-Up Layers}

The LULC layer was existent for five points in time: 1990, 1995, 2000, 2005 and 2010. For each year the LULC layer was reclassified to 6 classes (Forest, Grass, Water, Built-up, Bare Soil and Agriculture), while built-up area remained one single class. For each layer (1990, 1995 etc.) a zonal histogram was generated, meaning a table that depicts the count of cell values on the value input for each unique class.

\subsection{Extrapolation of the Population of Guangzhou}

The extrapolation of the urban population was based on the increase of population during the overall period of 1990-2005. However, calculations were performed for different observation periods, starting from different years, e.g. 1990-1995, 19902000, 1995-2005 etc. The average annual growth rate had to be calculated. (Husa and Wohlschlägl, 2004)

$$
r_{t, t+n}=\left(\sqrt[n]{\frac{P_{t+n}}{P_{t}}-1}\right)
$$

where:

$$
\begin{aligned}
& \mathrm{r}_{\mathrm{t}, \mathrm{t}+\mathrm{n}}=\text { average annual growth rate } \\
& \mathrm{n}=\text { number of periods (years) } \\
& \mathrm{Pt}=\text { population at the start of the observation } \\
& \text { period } \\
& \mathrm{P}_{\mathrm{t}+\mathrm{n}}=\text { population at the end of the observation } \\
& \text { period } \\
& \mathrm{t}, \mathrm{t}+\mathrm{n}=\text { observation period }
\end{aligned}
$$

Resulting rates were used for completing the estimation of the population until the final year of 2010. The most promising estimation was chosen: Based on the average annual growth rate of the years 1990-2005 (1.6\%), urban growth was then estimated for the years 2005-2010. The population extrapolation was computed for the total area of Guangzhou, assuming steady population growth rates.

$$
P_{t+x}=P_{t} *\left(1+\frac{r_{t+n}}{100}\right)^{x}
$$

where:

$$
\begin{aligned}
& \mathrm{P}_{t+\mathrm{x}}=\text { future population } \\
& \mathrm{Pt}=\text { base population (start of projection) } \\
& \mathrm{r}_{\mathrm{t}, \mathrm{t+n}}=\text { average annual growth rate } \\
& \mathrm{x}=\text { years projected into the future }
\end{aligned}
$$

The population forecast was related to built-up area (quantified in raster pixels). Knowing the average land consumption rate per capita e.g. for the year of 2005 and assuming constant values over time, the population extrapolation could be linked to it. The results showed the estimated growth of built-up area for the observation periods.

\subsection{Suitability Layer Calculation}

In order to visualize the spatial distribution of built-up area over time, a model for ArcGIS was set up, consisting of different raster analysis tools. The objective of the analysis was to create a layer showing the most favorable areas for urban settlements via combining different suitability layers.

Having estimated the growth of built-up area (raster pixels) for specific points in time, the raster pixels should be selected in the final suitability layer. The selected pixels should represent the highest values of the final suitability layer indicating the most favorable areas for the calculated growth of impervious surface in the year 2010 within the area under investigation. The results could then be compared to the real growth as indicated in the Land Use/Land Cover (LULC) raster for the year 2010.

The data for the ArcGIS model included the Land Use/Land Cover (LULC) raster 2005 and OpenStreetMap (OSM) data. OSM data was used to enhance the LULC 2005 data. In order to simulate a reliable growth scenario, OSM streets (Highways and Primary Roads) as well as OSM water bodies were used. The OSM data used for our study was adapted to the spatial resolution of the LULC raster dataset. (1 km x $1 \mathrm{~km})$. The OSM water bodies were combined with the LULC water areas.

The area most favorable for urban development should be close to existing urban settlement and big roads. Exclusion areas such as water bodies, already existing built-up areas and forest areas should be deleted from the final attractiveness layer. Because of the investigation of the frequency distribution of the reclassified LULC Layers from 1990 to 2010 (see 3.3 Preparation of builtup/non-built-up layer), it became obvious that forest areas have not changed significantly over time. Therefore, forest areas were regarded as exclusion areas. Due to the spatial resolution of the LULC raster dataset $(1 \mathrm{~km} \times 1 \mathrm{~km})$, the OSM water bodies were buffered by $200 \mathrm{~m}$ and could then be rasterized (Figure 2.). Since the quality of the OSM data set influences the result, a plausibility check was done. Further only high- and midlevel roads were taken into account that existence could be proven by visual inspection.

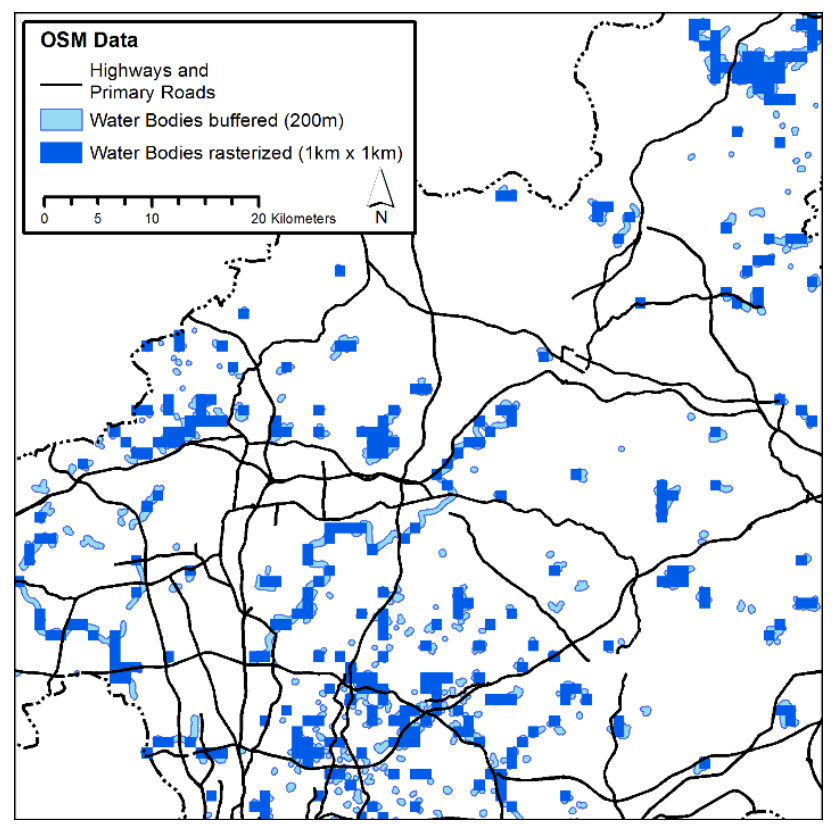

Figure 2. Rasterized water bodies

The particular suitability layers were calculated on a cell by cell basis. Due to the available data, a fuzzy site analysis was computed. Instead of classes with crisp boundaries (yes/no membership), the input layers were transformed to a 0 to 1 scale, indicating the degree of membership from low to high. In a first step Euclidian distances from the urban footprint (=Built-up) and from the major roads were calculated. A Fuzzy Membership Function ("linear") was computed, assuming a descending suitability within a growing distance. (DeMers, 2002) 


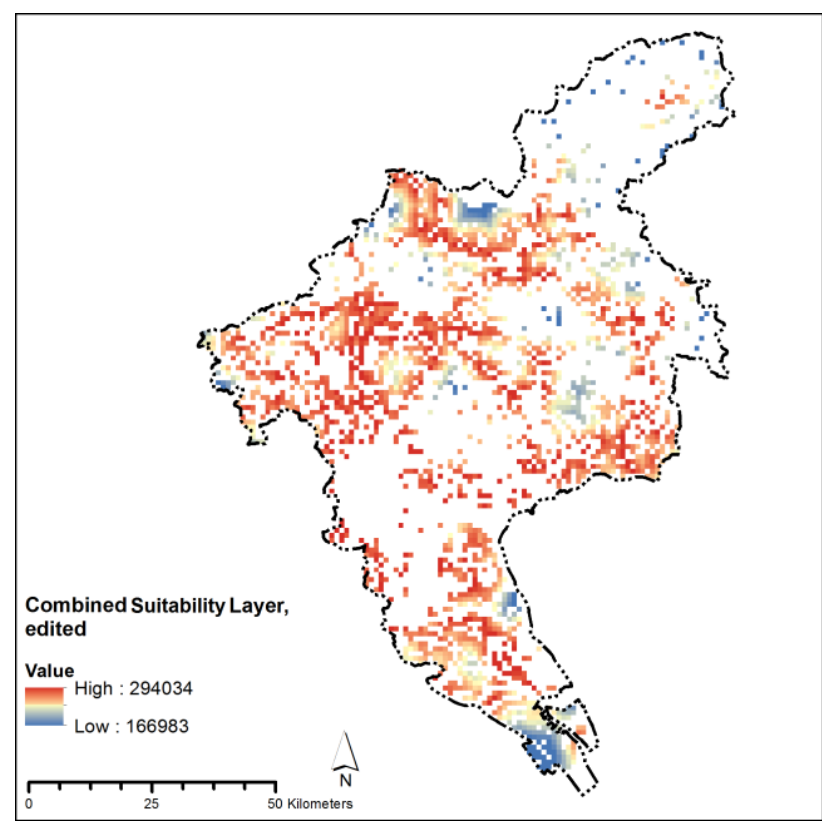

Figure 3. Combined Suitability Layer

The suitability layers were combined via the Raster Calculator Tool calculating the Sum of the raster datasets. Then, the Exclusion Areas (water bodies, the existing built-up area and the forest areas) were excluded (Figure 3.)

The final suitability layer was edited in order to obtain unique raster values which could be sorted in descending order. The values for the estimated growth of built-up area (96 raster pixels) could then be selected from the final attractiveness layer, indicating a possible urban growth. (Scenario A) Finally the actual data was taken into account and another scenario (Scenario B) was performed in order to verify the accuracy of the Suitability Layer Calculations. Actual data refers to the difference in the number of pixels of built-up area between the LULC layers of the year 2005 and the year 2010 (spatial resolution: $1 \mathrm{~km} \times 1 \mathrm{~km}$ ).

\section{RESULTS}

Starting in the year 1990 with an official number of 5.918 .462 people living within the administrative border of Guangzhou, an average annual growth rate of $1.6 \%$ for the years $1990-2005$ was calculated. From the year 1990 and the relation of 9.219 people that were represented by one pixel $(1 \mathrm{~km} \times 1 \mathrm{~km})$ of built-up area, urban growth led to a relation of 6.264 people per pixel in the year 2005. The predicted number of the population for the year 2010 was 8.067.340, compared to actual census data of 8.042.445 leading to a difference of (underestimated) 24.895 people (0.3\%). This estimation was set in relation to the relation of each pixel built-up area to the number of inhabitants for the year 2005 (6264 people per pixel) and yielded in the estimated number of 1288 pixel built up area for the year 2010. Compared to the actual data of the LULC layer of 2010 with 1.350 built-up pixels, a gap of 62 pixels could be quantified. ( $5 \%)$ Therefore the estimation produced a total number of 96 pixels that represented the growth of built-up area between the year 2005 and 2010. These 96 pixels were placed corresponding to the aforementioned methodology. This first scenario we named Scenario A. (Figure 4.)

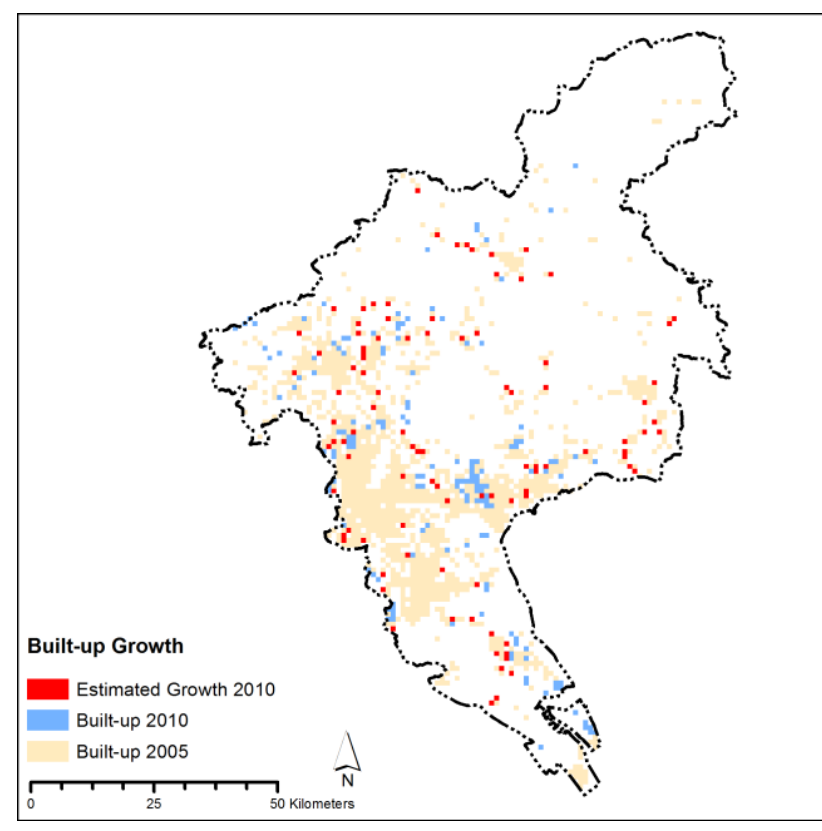

Figure 4. Scenario A

Comparing Scenario A and the actual LULC layer of the year 2010, 6 matching pixels could be stated. This means that 6 pixels (6\% matches) of the Scenario A overlapped with pixels of the LULC layer of 2010. Further the actual number of pixels representing the built-up area derived from the LULC layer of 2010 was used for Scenario B. Thus 159 pixels were used for the performance of Scenario B, resulting in a total number of $11(7 \%$ matches) pixels matching with the actual LULC layer (Figure 5.).

The building density of the generated pixels (Scenario A and B) is equal to the building density of the particular starting point due to the assumption of linear growth; in our case new pixels inherit the value of the pixels of the LULC layer of the year 2005.

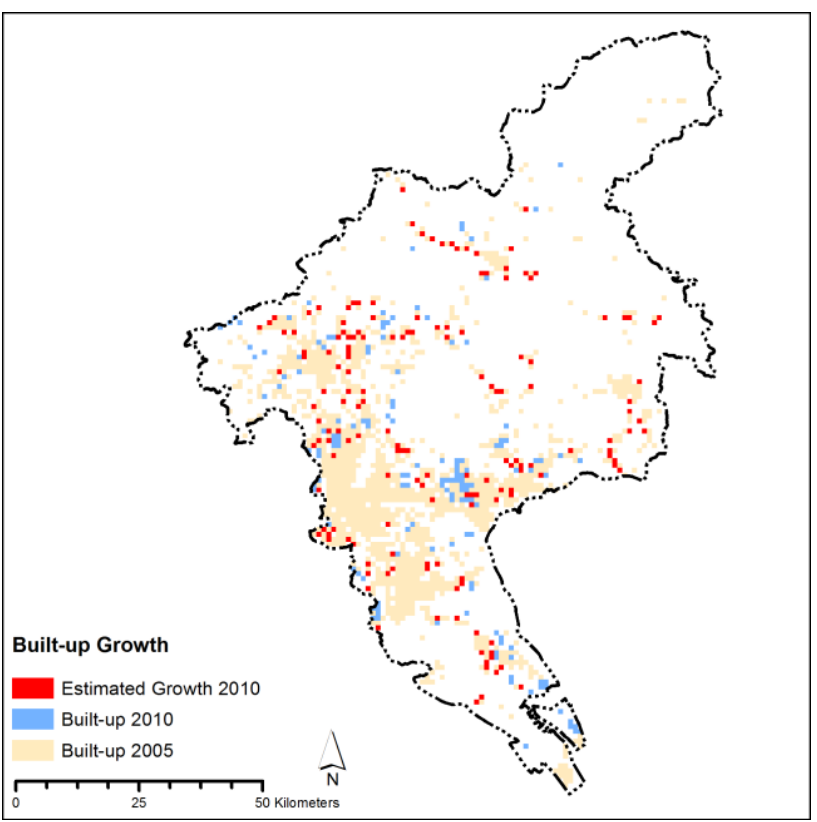

Figure 5. Scenario B 


\section{DISCUSSION}

The transfer of a model from one use case to another one may include several stumbling blocks. The authors recommend the limited use of input parameters as the presented study revealed that with increasing input parameters the transfer of a model becomes more difficult. The objective was to create a model that can be used globally. In order to meet this demand simplicity remains intrinsic and opens up the possibility for local experts to improve the model by adding site-specific input parameters such as orography, pollution, demographics etc. It is essential to use the same type of data that was used for the initial study. Differences in data may later cause problems; the real cause of such problems that occur during the computational process often cannot be comprehensively determined regarding their origin. In particular for urban growth models the authors suggest the use of data with consistent and equal quality: regarding satellite images (point in time, platform and spatial resolution), regarding census data (point in time, spatial resolution) and regarding Land Use/Land Cover data (point in time, classification methodology, spatial resolution). The administrative boundaries of several districts both in Ahmedabad and Guangzhou changed through the last 20 years. In such cases the inconsistency of data may impede the achievement of a certain degree of detail.

\section{CONCLUSION}

The results of the confirmability and the transferability study can be seen ambivalently. While the transferability of the existing model could easily be executed, the overall results of the visualisation are contrary to the authors' expectations. Although the exploration of the population of Guangzhou led to promising results and the suitability layer calculation could straightforwardly be performed, the overall accuracy remained rather low.

At the first glance, the distribution of the pixels of Scenario A appears arbitrary. However, after a second glance one does recognize a spatial pattern, starting from the North West and ending in the Middle East area of Guangzhou, (slightly but) corresponding to the actual trend of the LULC layer 2010 and the transport corridors of the Pearl River Delta Urban Cluster Coordination Plan.

After the comparison of Scenario A and B we assume three factors being responsible for the computed results, namely:

- the (coarse) resolution ( $1 \mathrm{~km} \mathrm{x} 1 \mathrm{~km})$ of LULC layers that were basis for our scenarios,

- the underestimation of pixels for the predicted year 2010 (gap of 62) that refers back to the ratio of people per pixel built-up area for the year 2005 (6.264) and

- weighting factors that favour urban growth alongside highways could not be applied due to missing data.

In contrast to the case study of Ahmedabad the spatial resolution for the city of Guangzhou was lower, also the spatial resolution of the census data was lower as data on a district level was not available. We could not apply the suitability layer used for the model of Ahmedabad that favoured sites with recent building activity for new built-up area due to inconsistencies within the LULC data. Furthermore, the urban growth model was initially used for the verification of a population forecast based on the scenario of limited open space for further building activity. Within the city of Guangzhou, land for building is not a limiting factor. The avoidance of urban sprawl and the conservation of connected rural areas are not leading points within current urban planning strategies.
We suggest further studies, using LULC based on a higher resolution (e.g. $30 \mathrm{~m}$ ), applying minimal weighting factors and taking into account the results and the experiences that were gained during this work.

To conclude, the study showed the transferability of the model for performance of urban growth scenarios by using freely available data and highlighted the advantages and the challenges that remain within its confirmability and usability for urban planners.

\section{REFERENCES}

Adhvaryu, B., 2010. Enhancing urban planning using simplified models: SIMPLAN for Ahmedabad, India. Prog. Plan. 73, 113207.

Agugiaro, G., 2015. Energy planning tools and CityGML-based 3D virtual city models: experiences from Trento (Italy). Appl. Geomat. 1-16.

Chen, J., Gao, J., Chen, W., 2016. Urban land expansion and the transitional mechanisms in Nanjing, China. Habitat Int. 53, 274283.

Chen, S., Zeng, S., Xie, C., 2000. Remote sensing and GIS for urban growth analysis in China. Photogramm. Eng. Remote Sens. $66,593-598$

DeMers, M.N., 2002. GIS modeling in raster. Wiley New York.

Downs, A., 2005. Smart growth: why we discuss it more than we do it. J. Am. Plann. Assoc. 71, 367-378.

Du, S., Shi, P., Van Rompaey, A., 2013. The relationship between urban sprawl and farmland displacement in the Pearl River Delta, China. Land 3, 34-51.

Gebetsroither-Geringer, E., Loibl, W., n.d. Urban Development and Infrastructure Cost Modelling for Managing Urban Growth in Latin American Cities.

Herold, M., Goldstein, N.C., Clarke, K.C., 2003. The spatiotemporal form of urban growth: measurement, analysis and modeling. Remote Sens. Environ. 86, 286-302.

Hu, T., Yang, J., Li, X., Gong, P., 2016. Mapping Urban Land Use by Using Landsat Images and Open Social Data. Remote Sens. 8, 151.

Husa, K., Wohlschlägl, H., 2004. Proseminar "Grundzüge der Bevölkerungsgeographie". Lehrbehelf zur Lehrveranstaltung. Universität Wien, Wien

Jat, M.K., Garg, P.K., Khare, D., 2008. Monitoring and modelling of urban sprawl using remote sensing and GIS techniques. Int. J. Appl. Earth Obs. Geoinformation 10, 26-43.

Lehner, A., Kraus, V., Steinnocher, K., 2016. URBAN GROWTH SCENARIOS OF A FUTURE MEGA CITY: CASE STUDY AHMEDABAD. ISPRS Ann Photogramm Remote Sens Spat. Inf Sci III-2, 165-172. doi:10.5194/isprs-annals-III-2-1652016

O’Looney, J., 1997. Beyond maps: GIS and decision making in local government. ESRI, Inc.

OSM, OSM - (C) OpenStreetMap contributors 
Rafiee, R., Mahiny, A.S., Khorasani, N., Darvishsefat, A.A., Danekar, A., 2009. Simulating urban growth in Mashad City, Iran through the SLEUTH model (UGM). Cities 26, 19-26.

Song, Y., Ding, C., 2009. Smart urban growth for China. Lincoln Institute of Land Policy.

Wu, F., 2015. Planning for growth: Urban and regional planning in China. Routledge.

Xiao, Y., Zhan, Q., 2009. A review of remote sensing applications in urban planning and management in China, in: Urban Remote Sensing Event, 2009 Joint. IEEE, pp. 1-5.

Yang, X., n.d. Use of Archival Landsat Imagery to Monitor Urban Spatial Growth. Urban Remote Sens. Monit. Synth. Model. Urban Environ. 15-33.

Zheng, H.W., Shen, G.Q., Wang, H., Hong, J., 2015. Simulating land use change in urban renewal areas: A case study in Hong Kong. Habitat Int. 46, 23-34. 